\title{
Orthogeriatrics prevents functional decline in hip fracture patients: report from two randomized controlled trials
}

Shams Dakhil ${ }^{1,2^{*}}$ D, Pernille Thingstad ${ }^{3}$, Frede Frihagen ${ }^{4}$, Lars Gunnar Johnsen ${ }^{3,5,6}$, Stian Lydersen ${ }^{7}$, Eva Skovlund ${ }^{8}$, Torgeir Bruun Wyller ${ }^{1,2}$, Olav Sletvold ${ }^{3,9}$, Ingvild Saltvedt ${ }^{3,9}$ and Leiv Otto Watne ${ }^{1}$

\begin{abstract}
Background: The incidence of hip fractures are expected to increase in the following years. Hip fracture patients have in addition to their fracture often complex medical problems, which constitute a substantial burden on society and health care systems. It is thus important to optimize the treatment of these patients to reduce negative outcomes. The aim of this study was to assess the effect of comprehensive orthogeriatric care (CGC) on basic and instrumental activities of daily living (B-ADL and I-ADL).

Methods: This study is based on two randomized controlled trials; the Oslo Orthogeriatric Trial and the Trondheim Hip Fracture Trial. The two studies were planned in concert, and data were pooled and analyzed using linear mixed models. I-ADL function was assessed by the Nottingham Extended ADL Scale (NEADL) and B-ADL by the Barthel $A D L(B A D L)$ at four and twelve months after surgery.

Results: Seven hundred twenty-six patients were included in the combined database, of which 365 patients received OC and 361 patients received CGC. For the primary endpoint, I-ADL at four months was better in the CGC group, with a between-group difference of 3.56 points ( $95 \% \mathrm{Cl} 0.93$ to 6.20, $p=0.008$ ). The between-group difference at 12 months was 4.28 points ( $95 \% \mathrm{Cl} 1.57$ to $7.00, p=0.002$ ). For B-ADL, between-group difference scores were only statistically significant at 12 months. When excluding the patients living at a nursing home at admission, both I-ADL and B-ADL function was significantly better in the CGC group compared to the OC group at all time points.

Conclusions: Merged data of two randomized controlled trials showed that admitting hip fracture patients to an orthogeriatric care unit directly from the emergency department had a positive effect on ADL up to twelve months after surgery.
\end{abstract}

Keywords: Orthogeriatric, Hip fracture, Activities of Daily living (ADL)

\footnotetext{
* Correspondence: shams.dakhil@studmed.uio.no

'Department of Geriatric Medicine, Oslo University Hospital, Oslo, Norway

${ }^{2}$ Institute of Clinical Medicine, University of Oslo, Oslo, Norway

Full list of author information is available at the end of the article
}

(c) The Author(s). 2021 Open Access This article is licensed under a Creative Commons Attribution 4.0 International License, which permits use, sharing, adaptation, distribution and reproduction in any medium or format, as long as you give appropriate credit to the original author(s) and the source, provide a link to the Creative Commons licence, and indicate if changes were made. The images or other third party material in this article are included in the article's Creative Commons licence, unless indicated otherwise in a credit line to the material. If material is not included in the article's Creative Commons licence and your intended use is not permitted by statutory regulation or exceeds the permitted use, you will need to obtain permission directly from the copyright holder. To view a copy of this licence, visit http://creativecommons.org/licenses/by/4.0/. The Creative Commons Public Domain Dedication waiver (http://creativecommons.org/publicdomain/zero/1.0/) applies to the data made available in this article, unless otherwise stated in a credit line to the data. 


\section{Background}

Patients suffering from a hip fracture are often frail; suffering multiple comorbidities, and are often subjected to polypharmacy [1]. The prefracture functional level of hip fracture patients has been found to be a strong and consistent predictor of short- and long-term rehabilitation outcome [2]. Only one third of patients return to their prefracture function, and one third will require further nursing home care [3]. Since the incidence is expected to increase, hip fractures will become a progressively larger public health burden [4-6].

Hip fracture patients are a large and resourcedemanding group. Several studies have shown that orthogeriatric care is beneficial regarding length of stay in hospital, waiting time to surgery, fewer surgical and medical complications and survival [7-15]. There are several different orthogeriatric models; ranging from orthopedic wards with a geriatric consultant service to an integrated care ward [7]. However, due to the heterogeneity of the different studies both in measured outcomes and study design, it is challenging to draw conclusions on what type of orthogeriatric care model is superior. In addition, most studies have evaluated the effect based on register data (mortality, length of stay, readmissions) and very few have assessed the effect based on a face-to-face evaluation of the patients in the months following discharge.

It has been argued that hip fracture patients benefit from an admission to a geriatric ward instead of an orthopedic ward [8, 16-19]. In such a model, "Geriatric and rehabilitation ward and orthopedic consultant service" according to Kammerlander [7], the patient is admitted directly from the emergency department to the geriatric ward. The patient has the entire stay (except for surgery) in the geriatric ward, and the orthopedics serve as consultants. Several studies have evaluated the effect of the implementation of such a model and the overall impression is that it is beneficial [20-24]. However, due to the heterogeneity in study design and outcomes, there is a need for multi-center studies which will allow for increased generalizability and give more precise estimates of the effect of such models.

Recently there have been two randomized controlled trials (RCTs) in Norway assessing the effect of this model; The Trondheim Hip Fracture Trial [25] and the Oslo Orthogeriatric Trial [1]. In both studies, the control group received traditional orthopedic care. The Oslo and Trondheim studies were planned in concert, and we have now merged data from these studies. This pooled data set will yield information from a larger and more heterogeneous group of hip fracture patients and increased statistical power will give more precise estimates of the effect of the model. The aim of the current study was to assess the effect of our orthogeriatric model on
Activities of Daily Living (ADL) - both instrumental ADL (I-ADL) and basic ADL (B-ADL) - four and twelve months after surgery.

\section{Methods}

Inclusion and randomization took place in the emergency department in the respective hospitals in both trials. In Oslo randomization was based on computergenerated random numbers (blocks of variable and unknown size) and was carried out by a statistician not involved in the clinical service. Randomization was also stratified according to whether or not the patients were admitted from nursing homes. In Trondheim patients were randomly assigned in a 1:1 ratio by a nurse. In both hospitals patients were transferred to the allocated wards directly from the emergency department. The intervention group received a CGC service preoperatively as well as postoperatively. Surgical and anesthesiologic procedures were similar in both groups. Four- and twelvemonth follow-up assessments were carried out at the hospital by study nurses blinded to group allocation. If the patients were unable to visit the hospitals the study nurses visited the patients where they were living at the specific time point and conducted the follow-up interview face to face. Since the intervention was at ward level, data collection during the index stay could not be blinded.

\section{Oslo orthogeriatric trial}

Recruitment lasted from September 2009 to January 2012 at Oslo University Hospital. All hip fracture patients were eligible for the trial, unless if the fracture was due to a high-energy trauma or if the patient was moribund at admission. Both home-dwelling patients and patients living in a nursing home at admission, at all ages were included, in total 329 patients [1].

Patients randomized to intervention were treated in the acute geriatric ward; both pre- and postoperatively. A team consisting of a geriatrician, nurse, physiotherapist and occupational therapist were responsible for delivering the CGC service. They were expected to assess patients during their first day on the ward, as well as conducting daily meetings to coordinate treatment and to plan discharge. The CGC service included medication reviews, early and intensive mobilization, optimizing pre- and postoperative nutrition and early discharge planning. Details about the clinical routines have been published [26].

The primary outcome for this study was cognitive function four months after surgery, and the secondary outcomes included delirium, delirium severity, length of stay, mortality, mobility, place of residence, Instrumental (I-ADL) and basic (B-ADL) function, and weight changes. The intervention had no impact on the primary 
outcome. However, better mobility (measured by the Short Physical Performance Battery (SPPB [27]) was found in home-dwelling patients [1].

\section{Trondheim hip fracture trial}

Recruitment lasted from April 2008 to December 2010 at St. Olavs Hospital, Trondheim University hospital. All home-dwelling patients above the age of 70 , and who were able to walk $10 \mathrm{~m}$ or more before the fracture were included $(n=397)$. Patients that had suffered a pathological fracture, undergone multiple traumas, or had a short life expectancy, as well as patients already living in a nursing home were excluded [25].

Patients randomized to intervention were treated in the geriatric ward with CGC service; both pre- and postoperatively. The CGC service included comprehensive medical assessment and treatment, early rehabilitation and early planning of discharge. Details about the clinical routines have been published [28].

For this study the primary outcome was mobility after four months measured by the SPPB, and secondary outcomes included I-ADL, B-ADL, cognition, quality of life, fear of falling, depression, gait control and daily physical activity. The study found a positive effect of the intervention on the primary outcome, and also on several of the secondary outcomes (I-ADL, B-ADL, fear of falling, quality of life, gait control and daily physical activity) [25].

\section{TOO HIP (the OsIO and Trondheim HIP fracture trial) database}

The Trondheim Hip Fracture Trial and the Oslo Orthogeriatrics Trial were planned in concert, and similar design and outcomes were chosen for future pooling of data as described in their protocols $[26,29]$. The goal was to make a larger and more heterogeneous database to provide the opportunity for more precise estimates on outcomes (Fig. 1). For assessing the effect of intervention on I-ADL and B-ADL function in the combined dataset, Nottingham Extended Activities of Daily Living Scale (NEADL) (range 0-66, higher scores indicate better function) [30] four months after surgery was chosen as the primary outcome. Secondary outcomes included NEADL at twelve months postoperatively, The Barthel ADL Index (BADL) (measures degree of independence

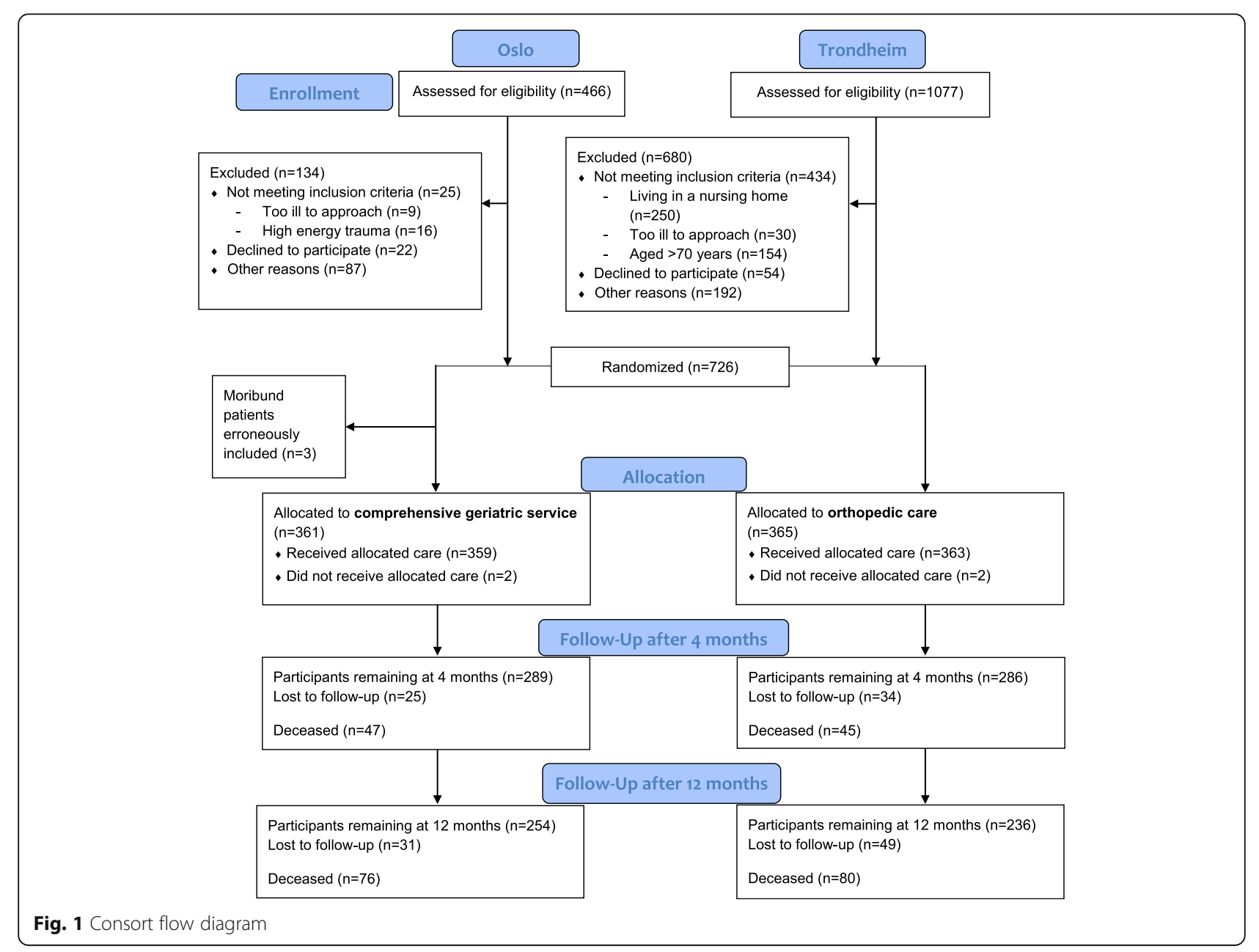


in ten basic ADL functions (range 0-20), higher scores indicate better function) [31] score at four and twelve months postoperatively, intra-hospital mortality and cumulative mortality at four and twelve months postoperatively, and new nursing home admissions.

\section{Statistical methods}

A statistical analysis plan was completed prior to any analyses [32]. The primary efficacy analysis was carried out using linear mixed model with NEADL as dependent variable, patient as random factor, time point (baseline, four months and twelve months) as fixed factor, and treatment group, site (Oslo versus Trondheim), age, sex, fracture type (extracapsular versus intracapsular), dwelling at home (versus nursing home), and the interaction between time points after inclusion and treatment group as covariates. Similar mixed model analyses were carried out with BADL score as the dependent variable. Dichotomous outcomes were analysed unadjusted, comparing proportions in the two treatment groups. In addition, they were compared using logistic regression, unadjusted, and adjusted for site, age, sex, fracture type and dwelling at home.

A two-sided p-value below 0.05 was taken as an indicator of statistical significance, and $95 \%$ confidence intervals $(\mathrm{CI})$ are reported where relevant. Missing items within the NEADL and BADL scales were imputed by the mean score for the remaining items that were answered, if at least $80 \%$ of the items on the scale were answered. Normality of residuals was checked by visual inspection of Q-Q-plots. All statistical analyses were done using IBM SPSS statistics 22-25.

\section{Results}

In total 726 patients were included in the combined database, of which 365 patients received traditional OC and 361 patients received CGC. Baseline characteristics did not differ between the groups (Table 1). Mean age was 83.0 years (SD 7.7), 542 (74.7\%) were women, and $102(14.0 \%)$ were living in a nursing home at admission. The groups were similar in function as measured by NEADL and BADL at baseline.

At four months the CGC group had better mean NEADL scores than the OC group with a betweengroup difference of 3.56 points (CI 0.93 to 6.20, $p=$ 0.008; Table 2). The between-group difference at twelve months was 4.28 points (CI 1.57 to $7.00, p=0.002$; Table 2).

For BADL; between-group difference scores were in favor of CGC on four and twelve months, but were only statistically significant at 12 months (4 month: betweengroup difference at 0.34 and CI 0.25 to $0.94, p=0.26$,
Table 1 Baseline characteristics

\begin{tabular}{|c|c|c|}
\hline & $\begin{array}{l}\text { Comprehensive } \\
\text { geriatric care } \\
(N=361) \\
\end{array}$ & $\begin{array}{l}\text { Orthopedic } \\
\text { care } \\
(N=365) \\
\end{array}$ \\
\hline Age, mean (SD) & $83.0(7.3)$ & $83.0(8.0)$ \\
\hline Male (\%) & $95(26.3)$ & $89(24.4)$ \\
\hline $\begin{array}{l}\text { Living in a nursing home at admission } \\
(\%)^{\mathrm{a}}\end{array}$ & $52(14.4)$ & $50(13.7)$ \\
\hline Barthel Index, mean $(S D)^{b}$ & $17.2(3.7)$ & $17.4(3.6)$ \\
\hline $\mathrm{NEADL}$, mean $(\mathrm{SD})^{\mathrm{c}}$ & $37.1(20.6)$ & $37.5(19.9)$ \\
\hline \multicolumn{3}{|l|}{ Type of fracture } \\
\hline - Extracapsular (\%) & $144(39.9)$ & $141(38.6)$ \\
\hline - Intracapsular (\%) & $217(60.1)$ & $224(61.4)$ \\
\hline \multicolumn{3}{|l|}{ Surgical treatment ${ }^{d}$} \\
\hline - Hemiarthroplasty (\%) & $148(41.2)$ & $155(42.8)$ \\
\hline - Osteosynthesis (\%) & $208(57.95)$ & $199(55.0)$ \\
\hline - Total hip replacement (\%) & $2(0.6)$ & $5(1.4)$ \\
\hline - Girdlestone (\%) & $1(0.3)$ & $0(0)$ \\
\hline - Not operated (\%) & $0(0)$ & $3(0.8)$ \\
\hline - Died before surgery & $2(0.6)$ & $3(0.8)$ \\
\hline Injury occurred indoors (\%) & $270(77.6)$ & $279(78.8)$ \\
\hline
\end{tabular}

$S D$ standard deviation, Barthel Index Barthel Index for Activities of Daily Living, NEADL Nottingham Extended Activities of Daily Living

apatients admitted from nursing homes were excluded in Trondheim

${ }^{\mathrm{b}}$ Barthel Index was missing from 10 in the orthopedic care group and 6 patients in the comprehensive geriatric care group

'NEADL was missing from 12 patients in the orthopedic care group and 9 patients in the comprehensive geriatric care group

${ }^{d}$ Information about surgical treatment was missing/unknown in 3 patients in the orthopedic care group and 2 patients in the comprehensive geriatric care group

${ }^{\mathrm{e}}$ Information about where the injury occurred (inside/outside) was unknown in 11 patients in the orthopedic care group and 13 patients in the comprehensive geriatric care group

and 12 months: between-group difference at 0.68 and $\mathrm{CI}$ 0.05 to $1.31, p=0.034$; Table 2).

When excluding the patients living at a nursing home at baseline, the ADL function was better in the intervention group at all time points; both for NEADL (4 months: between-group difference at 4.56 and $\mathrm{CI} 1.61$ to 7.52, $p=0.003$ and twelve months: between-group difference at 5.41 and CI 2.38 to 8.44, $p<0.001$; Table 3 ) and for BADL (four months: between-group difference at 0.67 and CI 0.06 to $1.28, p=0.030$ and twelve months: between-group difference at 0.97 and CI 0.34 to 1.60 , $p=0.003$; Table 3).

The mean preoperative waiting time was not different between groups ( 30.5 vs. 29.2 h, $p=0.76$; Table 4 ). Length of hospital stay was longer in the CGC group (mean 12.8 vs. 9.8 days $p<0.001$; Table 4). In-hospital mortality was the same between the groups (2.2 vs. $2.2 \%, p=0.98$; Table 4). Also, there was no significant difference in number of deaths at 4 months (13.0 vs. 
Table 2 Linear mixed model with NEADL and Barthel Index

\begin{tabular}{|c|c|c|c|c|c|c|}
\hline & \multicolumn{2}{|c|}{ Comprehensive geriatric care } & \multicolumn{2}{|c|}{ Orthopedic care } & \multicolumn{2}{|l|}{ Difference } \\
\hline & $\mathbf{N}$ & Mean (SE) & $\mathrm{N}$ & Mean (SE) & Estimate $(95 \% \mathrm{Cl})$ & $p$-value \\
\hline 4 months & 295 & & 291 & & & \\
\hline$N E A D L^{a}$ & 281 & $30.34(0.95)$ & 276 & $26.77(0.95)$ & $3.56(0.93$ to 6.20$)$ & 0.008 \\
\hline Barthel Index ${ }^{b}$ & 286 & $15.44(0.22)$ & 284 & $15.09(0.22)$ & $0.34(-0.25$ to 0.94$)$ & 0.26 \\
\hline 12 months & 260 & & 245 & & & \\
\hline NEADL ${ }^{c}$ & 253 & $30.59(0.97)$ & 234 & $26.31(0.99)$ & 4.28 (1.57 to 7.00$)$ & 0.002 \\
\hline Barthel Index ${ }^{d}$ & 251 & $15.46(0.22)$ & 234 & $14.78(0.23)$ & 0.68 (0.05 to 1.31$)$ & 0.034 \\
\hline $\begin{array}{l}\text { Linear mixed mode } \\
\text { after surgery) as fix } \\
\text { interaction betweer } \\
\text { SE standard error, } \\
\text { a NEADL at } 4 \text { month } \\
{ }^{6} \text { Barthel Index at } 4 \\
{ }^{C} N E A D L \text { at } 12 \text { mont }\end{array}$ & $\begin{array}{l}\text { EADL and } \\
\text {, and treat } \\
\text { id treatme } \\
\text { ence interv } \\
\text { g from } 15 \\
\text { missing fro } \\
\text { ng from } 11\end{array}$ & $\begin{array}{l}\text {, respectively, as d } \\
\text { site (Oslo versus T } \\
\text { tes } \\
\text { ttingham Extendec } \\
\text { he orthopedic care } \\
\mathrm{s} \text { in the orthopedic } \\
\text { the orthopedic care }\end{array}$ & $\begin{array}{l}\text { riable, } \\
\text { ge, sex } \\
\text { f Daily } \\
4 \text { patie } \\
\text { and fro } \\
7 \text { patie }\end{array}$ & $\begin{array}{l}\text { s random facto } \\
\text { e type, dwelling } \\
\text { cale, Barthel Ind } \\
\text { e comprehensi } \\
\text { ents in the com } \\
\text { e comprehensi }\end{array}$ & $\begin{array}{l}\text { oint (baseline, } 4 \text { months } \\
\text { e (versus nursing home) } \\
\text { activities of Daily Livir } \\
\text { ric care group } \\
\text { sive geriatric care group } \\
\text { ric care group }\end{array}$ & months \\
\hline
\end{tabular}

$12.3 \%, p=0.78)$ or 12 months ( 20.8 vs. $21.6 \%, p=0.78$ ) after surgery. There was a trend towards fewer new nursing home admissions in the CGC group at 4 months (16.9 vs. $20.9 \%, p=0.23)$ and 12 months (19.2 vs. $25.3 \%$, $p=0.11$; Table 4 ).

\section{Discussion}

The present study merged data from two Norwegian RCTs evaluating impact of CGC performed in acute geriatric wards compared to usual care in orthopaedic wards in treatment of hip-fracture patients. Our main result is that I-ADL was better in hip fracture patients treated with CGC as compared to usual care four and twelve months post-operatively. B-ADL as well, was better in the intervention group after twelve months. The effect of intervention on I-ADL and B-ADL was stronger when excluding patients admitted from a nursing home. A difference of 2.4 points on NEADL is considered to be clinically significant [33] and one point on BADL is the difference between being independent or not in basic ADL functions (walking, feeding, toilet use etc.). We therefore believe that the effects we find in our study is clinically relevant.

Our findings are in line with other studies conducted on a similar orthogeriatric care model as ours. In a quasi-RCT, Adunsky et al. showed that patients allocated to the intervention arm had almost a two-fold chance of successful rehabilitation outcome defined as more than $50 \%$ increase in "relative functional gain" [23]. Stenvall et al., conducted a prospective RCT and showed that significantly more patients allocated to intervention had regained independence in both I-ADL and B-ADL performance both four and twelve months after surgery, measured by the Katz Index of Independence in ADL [24]. To our knowledge these are the only other studies conducted in a geriatric ward with ADL as an end point. Other studies conducted in an orthopedic ward with varying geriatric liaison service have also evaluated the

Table 3 ADL excluding nursing home patients

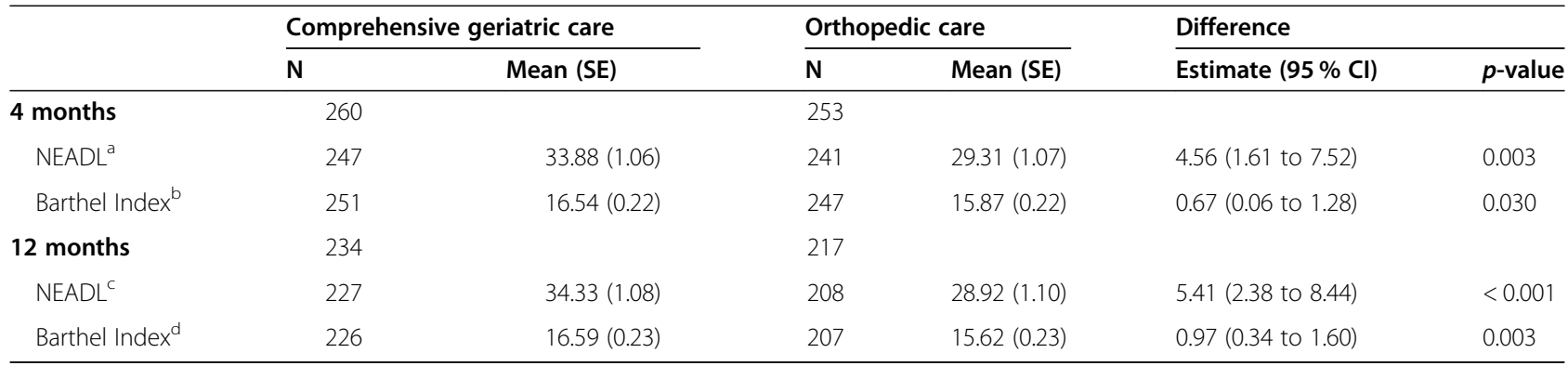

Linear mixed model with NEADL and Barthel Index, respectively, as dependent variable, patient as random factor, time point (baseline, 4 months and 12 months after surgery) as fixed factor, and treatment group, site (Oslo versus Trondheim), age, sex, fracture type, dwelling at home (versus nursing home), and the interaction between time and treatment as covariates

SE standard error, $95 \% \mathrm{Cl} 95 \%$ confidence interval, NEADL Nottingham Extended Activities of Daily Living scale, Barthel Index Barthel Activities of Daily Living index

${ }^{a}$ NEADL at 4 months missing from 12 patients in the orthopedic care group and 13 patients in the comprehensive geriatric care group

${ }^{\mathrm{b}}$ Barthel Index at 4 months missing from 6 patients in the orthopedic care group and from 9 patients in the comprehensive geriatric care group

'NEADL at 12 months missing from 9 patients in the orthopedic care group and 7 patients in the comprehensive geriatric care group

${ }^{\mathrm{d}}$ Barthel Index at 12 months missing from 10 patients in the orthopedic care group and missing 8 patients in the comprehensive geriatric care group 
Table 4 Impact of intervention during hospital stay, and 4 months and 12 months after hospital stay

\begin{tabular}{|c|c|c|c|}
\hline Hospital stay & Comprehensive geriatric care $(N=361)$ & Orthopedic care $(N=365)$ & $p$-value \\
\hline Waiting time for surgery in hours, mean (SD) ${ }^{a}$ & $30.5(26.8)$ & $29.2(19.1)$ & $0.76^{1}$ \\
\hline Length of stay in days, mean (SD) & $12.8(7.9)$ & $9.8(6.7)$ & $<0.001^{1}$ \\
\hline In-hospital mortality (\%) & $8(2.2)$ & $8(2.2)$ & $0.98^{2}$ \\
\hline 4 months after surgery & $\begin{array}{l}\text { Comprehensive geriatric care } \\
(N=295)\end{array}$ & $\begin{array}{l}\text { Orthopedic care } \\
(N=291)\end{array}$ & \\
\hline New nursing home admissions (\%) ${ }^{b}$ & $44(16.9)$ & $53(20.9)$ & $0.23^{2}$ \\
\hline 12 months after surgery & $\begin{array}{l}\text { Comprehensive geriatric care } \\
(N=260)\end{array}$ & $\begin{array}{l}\text { Orthopedic care } \\
(N=245)\end{array}$ & \\
\hline New nursing home admissions (\%) ${ }^{b}$ & $45(19.2)$ & $55(25.3)$ & $0.11^{2}$ \\
\hline \multicolumn{4}{|c|}{$\begin{array}{l}\text { SD standard deviation } \\
\text { aWaiting time for surgery in hours, defined as hours from admission to start of anesthesia, missing from } 7 \text { patients in the orthopaedic care group and } 2 \text { patients in } \\
\text { the comprehensive geriatric care group } \\
\text { bInformation about new nursing home admissions missing/unknown in } 2 \text { patients in the orthopedic care group at } 4 \text { months, and } 1 \text { patient in the orthopedic care } \\
\text { group at } 12 \text { months. Fifty patients from the orthopedic care group and fifty-two patients from the geriatric care group lived in a nursing home before the } \\
\text { hip fracture } \\
{ }^{1} \text { Mann-Whitney U Test } \\
{ }^{2} \text { Pearson Chi-Square test }\end{array}$} \\
\hline
\end{tabular}

effect of intervention on ADL; some have shown an effect of intervention [9, 19, 34-37], while others have only shown a trend [38] or no effect [39, 40].

The mean length of hospital stay was significantly longer in the intervention group in our study. A reduction of length of stay is often considered costeffective [41-44]. However, in addition to costs of the initial hospitalization there are several other aspects, such as re-admissions and need of rehabilitation and nursing homes. If longer length of stay results in increased ADL function it might therefore be beneficial for the society in the long run, as was also the conclusion in the Trondheim Hip Fracture Trial that calculated the full cost the first year after the hip fracture.

No other secondary outcome was significantly different between treatment groups in our study, including mortality, preoperative waiting time, and number of patients living in a nursing home four and twelve months after surgery. Some studies have reported reduced mortality after the introduction of orthogeriatric care $[8,10-16]$. The lack of effect on mortality in our study can be due to the fact that the mortality, compared to other studies, was already low before implementation of the orthogeriatric model [16].

Due to inclusion criteria, the Oslo study included more frail patients than the Trondheim study. We thus chose to include site (Oslo vs. Trondheim) as a covariate in the statistical analysis to correct for this.

When excluding the patients admitted from a nursing home, the effect of the intervention on ADL was stronger. One possible explanation is that the frailest patients already have lost much function and the potential for reduction of further decline therefore is limited. This does not mean that these patients do not benefit of orthogeriatric care, but other instruments than the ADL scales we have used might be better to evaluate the effect (quality of life, satisfaction among patients/carers). The more fit patients in our study benefitted the most. An interpretation is that those with best function are most prone to functional decline and that optimized care therefore is particularly important in this group. A concrete strategy based on these findings would be to categorize hip fracture patients already at admission into groups based on where they realistically could be discharged (e.g. (1) Home, (2) Rehabilitation. (3) Nursing home). Tailored intervention based on these groups might be a way to optimize use of resources and at the same time secure that patients with the largest potential for rehabilitation are prioritized, a strategy in line with recommendations based on register data on hip fracture patients in Norway [45].

\section{Strengths and limitations}

A strength of this study is the randomized controlled design of the included studies and the large sample size. Furthermore, both studies were planned in concert with future pooling of data in mind. Another strength is that patients were evaluated face to face by research nurses blinded to allocation four and twelve months after surgery. The wide inclusion criteria allowed for a heterogeneous study population and increase the generalizability of our findings. The different age distribution and differences regarding nursing home residents were accounted for by adjusting for these variables in the analyses, so we do not regard this as a limitation in the study. A limitation of the study is the lack of masking of both the patients and the staff delivering the treatment. 


\section{Conclusions}

Merged data of two RCTs conducted in Norway showed that administration of comprehensive geriatric care to hip fracture patients in an acute geriatric ward had a positive effect on I-ADL and B-ADL up to twelve months after surgery. The effect was strongest in homedwelling patients.

\section{Abbreviations}

RCTs: Randomized Controlled Trials; ADL: Activities of Daily Living; IADL: Instrumental Activities of Daily Living; B-ADL: Basic Activities of Daily Living; CGC: Comprehensive Geriatric Care; OC: Orthopedic Care; CGA: Comprehensive Geriatric Assessment; SPPB: Short Physical Performance Battery; NEADL: Nottingham Extended Activities of Daily Living; BADL: The Barthel ADL Index; Cl: Confidence Intervals

\section{Acknowledgements}

The authors would like to thank the patients and staff at the Orthopedic Department and the Geriatric Department at Oslo University Hospital and St. Olavs Hospital, Trondheim University hospital. They also thank research nurses Elisabeth Fragaat, Tone Fredriksen, Camilla Marie Andersen, Julie Ask Ottesen and Linda Feldt for assisting in data collection. Further we want to thank members of the study group in Trondheim especially Jorunn Helbostad, Anders Prestmo, Kristin Taraldsen and Sarah Lamb for their valid contribution in planning and performing the Trondheim part of the study.

\section{Authors' contributions}

SD combined the two datasets, analyzed an interpreted all patient data and prepared the manuscript. SL analyzed an interpreted all patient data, as well as preparing the "Statistical Methods" section and reviewing the manuscript. ES assisted in interpreting the data and reviewing the manuscript. LOW, TBW, IS, OS, PT, FF and LGJ designed, conducted and collected data from the trials, assisted in interpreting all patients data, as well as preparing and reviewing the manuscript. The author(s) read and approved the final manuscript.

\section{Funding}

The Oslo Orthogeriatric Trial was mainly funded by the Research Council of Norway. The Trondheim hip fracture study was funded by the Norwegian Research Council, the Central Norway Health Authority, the St. Olav Hospital Trust, the Department of Neuromedicine and Movement science, NTNU, the SINTEF and St. Olav Hospital Fund for Research and Innovation, and the Municipality of Trondheim. The sponsors had no role in the design and conduct of the study or methods, the collection, management, analysis, and interpretation of the data, or the preparation, review, and approval of the manuscript.

\section{Availability of data and materials}

The data that support the findings of this study are available on request from the corresponding author.

\section{Declarations}

\section{Ethics approval and consent to participate}

The Oslo Orthogeriatric Trial was registered with ClinicalTrials.gov (NCT01009268), and approved by the Regional Committee for Ethics in Medical Research in South East of Norway (REK 2009/450). The Trondheim Hip Fracture Trial was registered with ClinicalTrials.gov (NCT00667914), and approved by the Regional Committee for Ethics in Medical Research in Central Norway (REK4.2008.335). The Regional Committee for Ethics in Medical Research in South East of Norway and the Data Protection Officer at both hospitals approved merging of data from the two separate trials. Both studies were conducted in accordance with the Declaration of Helsinki. The patients or a proxy gave informed written consent to be included in the study before participation in both trials.

\section{Consent for publication}

Not applicabale.

\section{Competing interests}

I. Saltvedt has performed Alzheimer drug trial for Boehringer-Ingelheim 1346.0023. The remaining authors declare that they have no competing interests.

\section{Author details}

${ }^{1}$ Department of Geriatric Medicine, Oslo University Hospital, Oslo, Norway. ${ }^{2}$ Institute of Clinical Medicine, University of Oslo, Oslo, Norway. ${ }^{3}$ Department of Neuromedicine and Movement Science, Norwegian University of Science and Technology (NTNU), Trondheim, Norway. ${ }^{4}$ Division of Orthopedic Surgery, Oslo University Hospital, Oslo, Norway. ${ }^{5}$ Orthopedic Trauma Unit, Department of Orthopedic Surgery, St. Olavs Hospital, Trondheim University Hospital, Trondheim, Norway. ${ }^{6}$ Norwegian National Advisory Unit on Trauma, Division of Emergencies and Critical Care, Oslo University Hospital, Oslo, Norway. ${ }^{7}$ Department of Mental Health, Regional Centre for Child and Youth Mental Health and Child Welfare, Norwegian University of Science and Technology (NTNU), Trondheim, Norway. ${ }^{8}$ Department of Public Health and Nursing, Norwegian University of Science and Technology (NTNU), Trondheim, Norway. ${ }^{9}$ Department of Geriatrics, St. Olavs Hospital, Trondheim University Hospital, Trondheim, Norway.

Received: 3 September 2020 Accepted: 14 March 2021

Published online: 25 March 2021

\section{References}

1. Watne LO, Torbergsen AC, Conroy S, Engedal K, Frihagen F, Hjorthaug GA, et al. The effect of a pre- and postoperative orthogeriatric service on cognitive function in patients with hip fracture: randomized controlled trial (Oslo Orthogeriatric Trial). BMC Med. 2014;12:63.

2. Kristensen MT. Factors affecting functional prognosis of patients with hip fracture. Eur J Phys Rehabil Med. 2011;47(2):257-64.

3. Kammerlander C, Doshi HK, Bocker W, Gosch M. Fragility Fracture Care and Orthogeriatric Comanagement. BioMed research international. 2016;2016: 2056376.

4. Veronese N, Maggi S. Epidemiology and social costs of hip fracture. Injury. 2018;49(8):1458-60.

5. Cheng SY, Levy AR, Lefaivre KA, Guy P, Kuramoto L, Sobolev B. Geographic trends in incidence of hip fractures: a comprehensive literature review. Osteoporosis Int. 2011;22(10):2575-86.

6. Hernlund E, Svedbom A, Ivergard M, Compston J, Cooper C, Stenmark J, et al. Osteoporosis in the European Union: medical management, epidemiology and economic burden. A report prepared in collaboration with the International Osteoporosis Foundation (IOF) and the European Federation of Pharmaceutical Industry Associations (EFPIA). Arch Osteo. 2013;8:136.

7. Kammerlander C, Roth T, Friedman SM, Suhm N, Luger TJ, KammerlanderKnauer $U$, et al. Ortho-geriatric service-a literature review comparing different models. Osteo Int. 2010:21(Suppl 4):S637-46.

8. Grigoryan KV, Javedan $\mathrm{H}$, Rudolph JL. Orthogeriatric care models and outcomes in hip fracture patients: a systematic review and meta-analysis. J Orthop Trauma. 2014;28(3):e49-55.

9. Lin SN, Su SF, Yeh WT. Meta-analysis: Effectiveness of Comprehensive Geriatric Care for Elderly Following Hip Fracture Surgery. West J Nurs Res. 2020;42(4):293-305.

10. Stenqvist C, Madsen CM, Riis T, Jorgensen HL, Duus BR, Lauritzen JB, et al. Orthogeriatric Service Reduces Mortality in Patients With Hip Fracture. Geriatric orthopaedic surgery rehabilitation. 2016;7(2):67-73.

11. Barone A, Giusti A, Pizzonia M, Razzano M, Palummeri E, Pioli G. A comprehensive geriatric intervention reduces short- and long-term mortality in older people with hip fracture. J Am Geriatr Soc. 2006;54(7): $1145-7$

12. Folbert EC, Hegeman $\mathrm{JH}$, Vermeer $M$, Regtuijt EM, van der Velde $\mathrm{D}$, Ten Duis $\mathrm{HJ}$, et al. Improved 1-year mortality in elderly patients with a hip fracture following integrated orthogeriatric treatment. Osteo Int. 2017;28(1):269-77.

13. Henderson CY, Shanahan E, Butler A, Lenehan B, O'Connor M, Lyons D, et al Dedicated orthogeriatric service reduces hip fracture mortality. Ir J Med Sci. 2017;186(1):179-84.

14. Suarez S, Pesantez RF, Diaz ME, Sanchez D, Tristancho LU, Vanegas MV, et al. Impact on Hip Fracture Mortality After the Establishment of an Orthogeriatric Care Program in a Colombian Hospital. J Aging Health. 2017; 29(3):474-88. 
15. Zeltzer J, Mitchell RJ, Toson B, Harris IA, Ahmad L, Close J. Orthogeriatric services associated with lower 30-day mortality for older patients who undergo surgery for hip fracture. The Medical journal of Australia. 2014; 201(7):409-11.

16. Moyet J, Deschasse G, Marquant B, Mertl P, Bloch F. Which is the optimal orthogeriatric care model to prevent mortality of elderly subjects post hip fractures? A systematic review and meta-analysis based on current clinical practice. Int Orthop. 2019;43:1449-54.

17. Sabharwal $\mathrm{S}$, Wilson $\mathrm{H}$. Orthogeriatrics in the management of frail older patients with a fragility fracture. Osteo Int. 2015;26(10):2387-99.

18. Shields L, Henderson V, Caslake R. Comprehensive Geriatric Assessment for Prevention of Delirium After Hip Fracture: A Systematic Review of Randomized Controlled Trials. J Am Geriatr Soc. 2017;65(7):1559-65.

19. Mukherjee K, Brooks SE, Barraco RD, Como JJ, Hwang F, Robinson BRH, et al. Elderly adults with isolated hip fractures- orthogeriatric care versus standard care: A practice management guideline from the Eastern Association for the Surgery of Trauma. J Traum Acute Care Surg. 2020;88(2):266-78.

20. Boyd RV, Hawthorne J, Wallace WA, Worlock PH, Compton EH. The Nottingham orthogeriatric unit after 1000 admissions. Injury. 1983;15(3):193-6.

21. Miura LN, DiPiero AR, Homer LD. Effects of a geriatrician-led hip fracture program: improvements in clinical and economic outcomes. J Am Geriatr Soc. 2009;57(1):159-67.

22. Adunsky A, Lerner-Geva L, Blumstein T, Boyko V, Mizrahi E, Arad M. Improved survival of hip fracture patients treated within a comprehensive geriatric hip fracture unit, compared with standard of care treatment. J Am Med Dir Assoc. 2011;12(6):439-44.

23. Adunsky A, Lusky A, Arad M, Heruti RJ. A comparative study of rehabilitation outcomes of elderly hip fracture patients: the advantage of a comprehensive orthogeriatric approach. J Gerontol Series A Biol Sci Med Sci. 2003;58(6):542-7.

24. Stenvall M, Olofsson B, Nyberg L, Lundstrom M, Gustafson Y. Improved performance in activities of daily living and mobility after a multidisciplinary postoperative rehabilitation in older people with femoral neck fracture: a randomized controlled trial with 1-year follow-up. J Rehabil Med. 2007;39(3): 232-8.

25. Prestmo A, Hagen G, Sletvold O, Helbostad JL, Thingstad P, Taraldsen K, et al. Comprehensive geriatric care for patients with hip fractures: a prospective, randomised, controlled trial. Lancet. 2015;385(9978):1623-33.

26. Wyller TB, Watne LO, Torbergsen A, Engedal K, Frihagen F, Juliebo V, et al. The effect of a pre- and post-operative orthogeriatric service on cognitive function in patients with hip fracture. The protocol of the Oslo Orthogeriatrics Trial. BMC Geriatr. 2012;12:36.

27. Guralnik JM, Ferrucci L, Simonsick EM, Salive ME, Wallace RB. Lowerextremity function in persons over the age of 70 years as a predictor of subsequent disability. N Engl J Med. 1995;332(9):556-61.

28. Sletvold O, Helbostad JL, Thingstad P, Taraldsen K, Prestmo A, Lamb SE, et al. Effect of in-hospital comprehensive geriatric assessment (CGA) in older people with hip fracture. The protocol of the Trondheim Hip Fracture trial. BMC Geriatr. 2011;11:18.

29. Saltvedt I, Prestmo A, Einarsen E, Johnsen LG, Helbostad JL, Sletvold O. Development and delivery of patient treatment in the Trondheim Hip Fracture Trial. A new geriatric in-hospital pathway for elderly patients with hip fracture. BMC Res Notes. 2012:5:355.

30. Gladman JR, Lincoln NB, Adams SA. Use of the extended ADL scale with stroke patients. Age Ageing. 1993;22(6):419-24

31. Wade DT. Measurement in neurological rehabilitation. Curr Opin Neurol Neurosurg. 1992;5(5):682-6.

32. Dakhil S. Statistical Analysis Plan - TOO HIP 2017 [Available from: http://folk. uio.no/tbwyller/Statistical_analysis_plan_TOO_HIP.pdf.

33. Wu CY, Chuang LL, Lin KC, Lee SD, Hong WH. Responsiveness, minimal detectable change, and minimal clinically important difference of the Nottingham Extended Activities of Daily Living Scale in patients with improved performance after stroke rehabilitation. Arch Phys Med Rehabil. 2011;92(8):1281-7.

34. Shyu YI, Liang J, Wu CC, Su JY, Cheng HS, Chou SW, et al. Interdisciplinary intervention for hip fracture in older Taiwanese: benefits last for 1 year. J Gerontol Series A Biol Sci Med Sci. 2008;63(1):92-7

35. Shyu YI, Liang J, Wu CC, Su JY, Cheng HS, Chou SW, et al. Two-year effects of interdisciplinary intervention for hip fracture in older Taiwanese. J Am Geriatr Soc. 2010:58(6):1081-9.
36. Shyu Yl, Liang J, Wu CC, Su JY, Cheng HS, Chou SW, et al. A pilot investigation of the short-term effects of an interdisciplinary intervention program on elderly patients with hip fracture in Taiwan. J Am Geriatr Soc. 2005:53(5):811-8.

37. Doshi HK, Ramason R, Azellarasi J, Naidu G, Chan WL. Orthogeriatric model for hip fracture patients in Singapore: our early experience and initial outcomes. Arch Orthop Trauma Surg. 2014;134(3):351-7.

38. Vidan M, Serra JA, Moreno C, Riquelme G, Ortiz J. Efficacy of a comprehensive geriatric intervention in older patients hospitalized for hip fracture: a randomized, controlled trial. J Am Geriatr Soc. 2005;53(9):1476-82.

39. Deschodt M, Braes T, Broos P, Sermon A, Boonen S, Flamaing J, et al. Effect of an inpatient geriatric consultation team on functional outcome, mortality, institutionalization, and readmission rate in older adults with hip fracture: a controlled trial. J Am Geriatr Soc. 2011;59(7):1299-308.

40. Swanson CE, Day GA, Yelland CE, Broome JR, Massey L, Richardson HR, et al. The management of elderly patients with femoral fractures. A randomised controlled trial of early intervention versus standard care. The Medical journal of Australia. 1998;169(10):515-8.

41. Elliot JR, Wilkinson TJ, Hanger HC, Gilchrist NL, Sainsbury R, Shamy S, et al. The added effectiveness of early geriatrician involvement on acute orthopaedic wards to orthogeriatric rehabilitation. N Z Med J. 1996; 109(1017):72-3

42. Leung FK, Lau TW, Yuen GW, Chan EM, Chan P, Lam RY. Effectiveness of a multidisciplinary approach to geriatric hip fractures in improving clinical outcomes and cost of care. Hong Kong Med J. 2018;24Suppl 2(1):45-7.

43. Patel JN, Klein DS, Sreekumar S, Liporace FA, Yoon RS. Outcomes in Multidisciplinary Team-based Approach in Geriatric Hip Fracture Care: A Systematic Review. J Am Acad Orthop Surg. 2020;28(3):128-33.

44. Sayeed Z, Anoushiravani A, El-Othmani M, Barinaga G, Sayeed Y, Cagle P Jr, et al. Implementation of a Hip Fracture Care Pathway Using Lean Six Sigma Methodology in a Level I Trauma Center. J Am Acad Orthop Surg. 2018; 26(24):881-93.

45. Ranhoff AH, Holvik K, Martinsen MI, Domaas K, Solheim LF. Older hip fracture patients: three groups with different needs. BMC Geriatr. 2010;10:65.

\section{Publisher's Note}

Springer Nature remains neutral with regard to jurisdictional claims in published maps and institutional affiliations.

Ready to submit your research? Choose BMC and benefit from:

- fast, convenient online submission

- thorough peer review by experienced researchers in your field

- rapid publication on acceptance

- support for research data, including large and complex data types

- gold Open Access which fosters wider collaboration and increased citations

- maximum visibility for your research: over $100 \mathrm{M}$ website views per year

At $\mathrm{BMC}$, research is always in progress.

Learn more biomedcentral.com/submissions 